\title{
Celebrating the Last 30 Years of NODA Annual Conferences
}

\author{
Sheena C. Williams and Denise L. Rode
}

One of the enduring hallmarks of the National Orientation Directors Association has been its outstanding annual conferences. In fact, NODA and NODAC (National Orientation Directors Annual Conference) have been nearly synonymous to many orientation professionals over the years. The annual conferences have been noted for their unparalleled creativity, for building inclusive communities, and for embracing all levels of staff working with orientation and transition programs-from undergraduate students to seasoned professionals, from faculty to graduate students and emerging professionals.

For many past and present NODA members, annual conferences (and their regional counterparts) provide a time of networking, learning, inspiration, and connecting with friends old and new. Indeed, higher education professionals who have worked in other student or academic affairs units are often struck by the collegiality and spirit of camaraderie they find at NODA conferences. For many, NODA has become their professional development "home base," complete with long-standing friendships that seem to transcend job changes, retirements, and other life transitions.

Members grieve with each other when a death occurs and rejoice with each other on happy occasions such as weddings, commitment ceremonies, and births or adoptions of children. They also provide sounding boards for each other during difficult work situations and career changes, and many a program idea has been hatched over dinner in the conference city or during conversations in conference hotel lobbies or bars. For many, NODAC is the most anticipated professional development opportunity of the year-a time of rejuvenation, of sharing frustrations and successes, of strengthening ties to our profession and renewing our common commitment to serving new students and their families.

On the occasion of NODA's 30th anniversary, editors Denise Rode and Sheena Williams have taken a look back in time at the past 30 years of annual NODA conferences. While orientation conferences have been held for more than 50 years - the first occurring in Columbus, Ohio in 1948-the editors had access to only approximately 30 years' worth of conference programs; unfortunately, they were unable to document several conferences. Appendices A and $\mathrm{B}$ describe the years, locations, themes, host institutions, speakers, and special features and topics of many annual conferences. Those conferences documented reveal increasing sophistication in programming in tandem with the growth and complexity of the organization. 


\section{Content Analysis of the Last 30 Years of NODAC Presentations}

An analysis was conducted on the NODA conference programs for approximately the last 30 years. Because the researcher did not have access to programs for all of last 30 conferences, the review began with the earliest program available (1979) and continued for each year available after that, through 2006. In total, 18 conference programs were reviewed, and 1,279 session topics were classified into the following 13 categories: (a) Program Administration; (b) Program Formats (overall structure of programs); (c) Program Components (specific elements within a program); (d) Staffing; (e) Extended Orientation/ Programs (i.e., first-year experience courses, welcome activities); (f) Family Orientation/Transition; (g) Special Populations; (h) Student Development; (i) Professional Development; (j) Technology; (k) NODA; (l) Special Interest; and (m) Trends, Theory, and Research (see Table 1 for data).

The most common session topic was Program Administration, with 181 sessions (14.2\% of the conference sessions). Topics covered in these sessions included program changes, budgeting and funding, program evaluation and development, the use of CAS Standards, customer service, program involvement from faculty and other institutional offices, ethics, student-run programs, marketing and publications, general staff supervision and development, and campus crisis management.

TABLE 1

\section{Number of Conference Sessions by Topic}

Session Topics

Program Administration

Professional Development

Program Components

Staffing

Special Populations

Extended Orientation/Programs

Special Interest

Family Orientation/Transitions

Misc.

Program Formats

NODA

Technology

Trends, Theory, \& Research

Student Development

Total
Number of Sessions

$\%$ of Total

181

175

169

13.7

154

13.2

142

12.0

11.1

97

7.6

78

6.1

72

5.6

47

3.7

41

3.2

37

2.9

33

2.6

33

2.6

20

1.6

1,279

$100 \%$ 
Professional Development comprised 13.7\% (N=175) of the conference sessions. Presentations in this category included professional roles, idea exchanges, writing for publication, professional development of student staff, career development/goals, professional associations/involvement, time and staff management, communication skills, diversity awareness, networking, NODA internships, ethics, and leadership development.

With 169 sessions, Program Components made up 13.2\% of the total conference sessions, making it the third most frequent session category. Components represented in this category included peer advisement, program publications, academic advising and placement exams, games and icebreakers, student characteristics surveys, academic planners, student-faculty interaction, educational planning, college simulation, community service projects, multimedia components, diversity awareness, and educational components. Sessions given on educational components were about integrating educational elements about drugs, alcohol, sex, STDs, sexual assault, relationships, debt/credit education, and general social issues into orientation programs. These sessions comprised $21.9 \%(\mathrm{~N}=37)$ of the total Program Components presentations.

Conference sessions on Staffing totaled 154 (12\% of the total). These sessions included topics such as orientation staff recruitment, selection, and training; supervision, evaluation, and development of professional, paraprofessional, and student staff; team building and team dynamics; staff diversity; conflict management; and ethics and sensitivity training.

There were 142 sessions given on Special Populations, making this category $11.1 \%$ of the total. Populations represented included nontraditional, returning, and adult students; students with disabilities; commuter and off-campus students; international and minority students; transfer students; student athletes; high-risk students and students admitted conditionally; mid-year entry and reentry students; students undecided about a major; graduate students; online students; first-generation students; and lesbian, gay, bisexual, and transgender (LGBT) students.

Sessions covering Extended Orientation/Programs comprised 7.6\% ( $\mathrm{N}=97)$ of the total conference sessions. Programs discussed in these sessions included first-year experience and orientation courses, freshmen seminars, preview/welcome weeks, peer outreach, new student convocation, pre-orientation programs, reading programs, and freshmen interest groups.

Special Interest sessions made up $78(6.1 \%)$ of the total conference sessions. Primarily, this category was comprised of the conference caucus and network meetings, which concerned the interests of such groups as undergraduate and graduate students; two-year and community colleges; minority and multi-ethnic students and members; re-entry, adult, and nontraditional students; new and seasoned professionals; Canadian institutions and members; small and large colleges; LGBT students and members; parents; and transfer students. Social justice was also a topic covered in the special interest sessions.

Sessions that discussed parent, family, or sibling programs; bilingual family programs; educational components to family programs; and parent listservs comprised the Family Orientation/Transitions category. This category had 72 
sessions, making it $5.6 \%$ of the total conference presentations.

With 41 conference sessions, Program Formats made up 3.2\% of the total sessions. Overall formats discussed in these sessions included 2-day programs; summer workshops; advising, orientation, assessment, and registration programs; 4-hour orientation programs; off-campus programs; video conference programs; and online programs.

Some conference sessions were very specific to the National Orientation Directors Association and, therefore, comprised the NODA category of conference presentations. Thirty-seven sessions $(2.9 \%)$ were categorized as being NODArelated and included meetings for conference planning or hosting, professional involvement in the association, information on the NODA Data Bank, presenters' meetings, Board of Directors' meetings, committee meetings, and meetings for strategic planning for the association.

Technology sessions made up 2.6\% ( $\mathrm{N}=33)$ of the total conference sessions. Topics included multimedia productions (many being "how-to" presentations), computer assistance in orientation programs, computerized academic placement tests, computerized orientation reservation systems, Web sites, campus computer use policies, data base development, online student support, Blackboard, and online communities (such as Facebook).

Conference sessions concerning Trends, Theory, and Research also comprised $2.6 \%(\mathrm{~N}=33)$ of the total. These sessions covered the following topics: (a) appropriately supportive academic orientations, (b) research on student study habits and attitudes, (c) factors present when students choose institutions, (d) orientation's role in enrollment management, (e) orientation's impact on grade point average and college, (f) trends in orientation, (g) implications for control-mastery theory in orientation, (h) trends and theory for academic support, (i) theory for enhancing the first-year experience, (j) theories surrounding the appropriate "home" for orientation-student or academic affairs, (k) organizational and developmental theories, (l) student learning outcomes, (m) trends in parents' expectations, and (n) Millennial theory.

There were 20 sessions (1.6\% of the total) that fell into the Student Development category. Topics covered in these sessions included student and leadership involvement, decision-making and time-management skills, involvement of orientation leaders (both during and after orientation programs) as a vehicle for student development, developing responsible citizens from college students, and graduate internships.

Forty-seven $(3.7 \%)$ of the total conference sessions did not fit directly into one of the 13 categories. These sessions were labeled as "Miscellaneous" and included such diverse topics as student services, student-faculty interactions, retention and recruitment, personal development, academic affairs, student characteristics, student transition, and federal laws and regulations (such as FERPA). 
In order to take a broader look at the data gathered during this study, the researcher broke down the 30 years of conferences into three 10-year periods: 1977-1986 (Decade 1), 1987-1996 (Decade 2), and 1997-2006 (Decade 3). During the first decade, the most common session topics were Program Administration ( $\mathrm{N}=60 ; 16.6 \%$ of the total presentations for Decade 1), Special Populations ( $\mathrm{N}=57 ; 15.7 \%$ of the total presentations for Decade 1$)$, and Staffing ( $N=46 ; 12.7 \%$ of the total presentations for the first decade). In Decade 2, the most frequent session topics were Professional Development $(\mathrm{N}=84 ; 15.8 \%$ of the total sessions for the second decade), Program Components ( $\mathrm{N}=78 ; 14.7 \%$ of the total for Decade 2), and Program Administration (N=71; 13.3\% of the total for Decade 2). From 1997-2006, the most common session topics were also Professional Development ( $\mathrm{N}=57 ; 14.8 \%$ of the total presentations for Decade 3), Program Components ( $\mathrm{N}=51 ; 13.2 \%$ of the total for the third decade), and Program Administration ( $\mathrm{N}=50 ; 13 \%$ of the total for Decade 3).

There were other notable trends in the conference session data collected for the last 30 years. The category of Technology showed the largest rise in session numbers during the third decade (going from 8 sessions in each of the first two decades to 17 sessions in Decade 3). Special Populations had the largest decrease in session numbers in Decade 3, going from 57 to 58 sessions in the first and second decade, respectively, to only 27 sessions in the third decade (see Figure 1).

\section{Topic trends observed over three decades of conference sessions.}

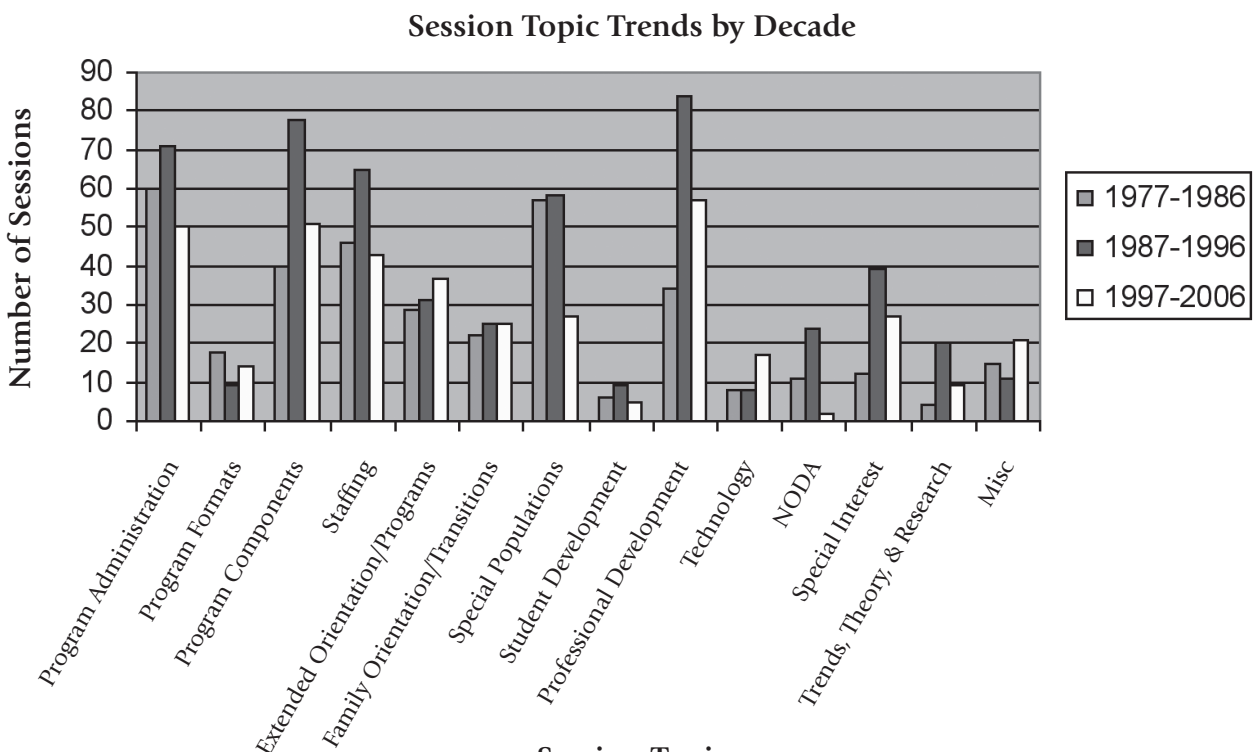

Session Topic 
It should be mentioned that the comparative trends indicated in this section may not show significant differences, as there was not an equal number of sessions reviewed for each decade, nor was there an equal number of conferences reviewed per decade. As seen in Table 2, the researcher only had four conference programs to review for Decade 3, as compared to seven conference programs reviewed for each of the first two decades. The number of sessions reviewed per decade also differed across the decades, but not necessarily in direct correlation with the number of conferences reviewed. Decade 1 and Decade 3 had more similar session numbers, with 362 and 385 sessions reviewed, respectively. The second decade, however, had 532 sessions, despite having had an equal number of conference programs reviewed as Decade 1. Because of these variances in available data, caution should be used when comparing the overall trends in numbers of sessions by decade.

TABLE 2

\section{Number of Sessions by Decade Compared to Number of Conferences Reviewed}

\begin{tabular}{lrrrrr} 
Presentation Topics & 1977-1986 & $\mathbf{1 9 8 7 - 1 9 9 6}$ & $\mathbf{1 9 9 7 - 2 0 0 6}$ & Total \\
\hline No. of Sessions Reviewed & 358 & 512 & 376 & 1,246 \\
No. of Conferences Reviewed & 7 & 7 & 4 & 18
\end{tabular}




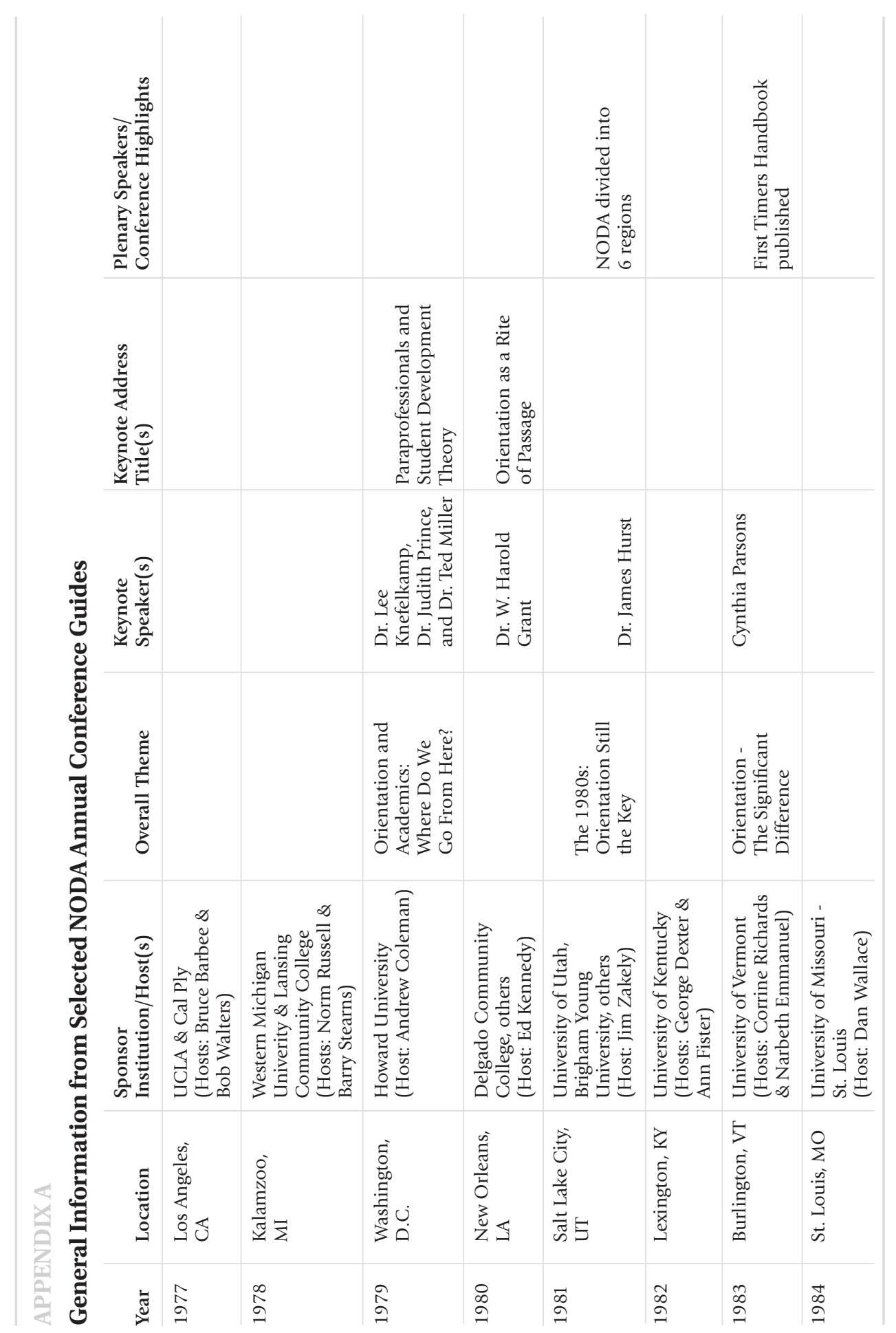



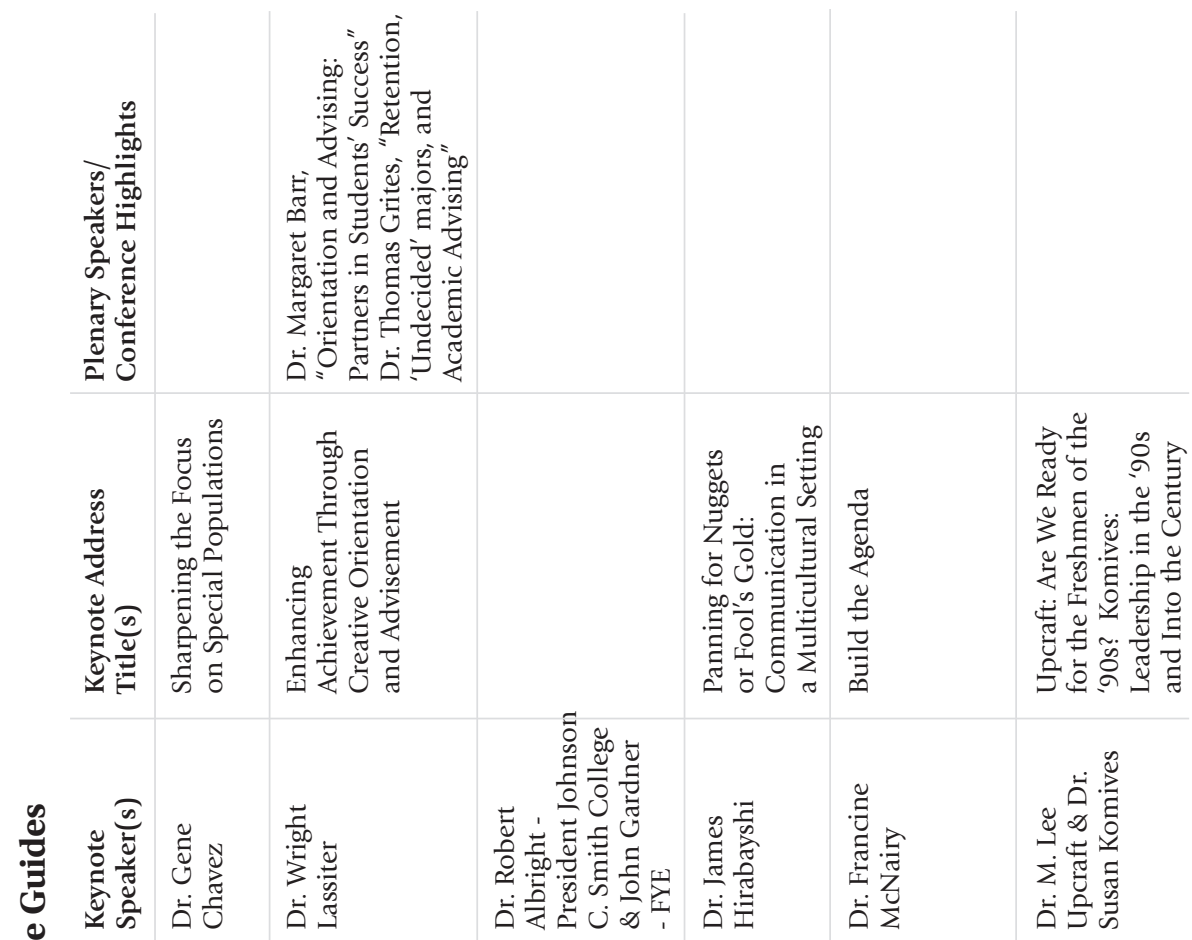

䓛気

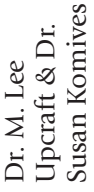

常

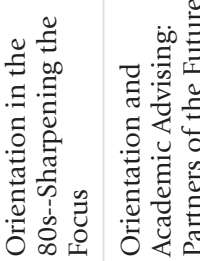

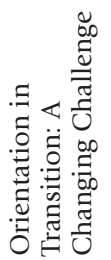

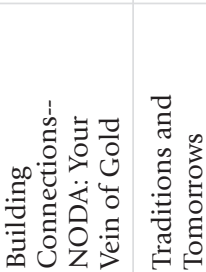

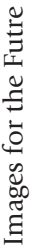

을

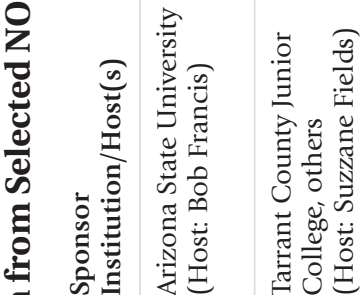

की स बंध

弪泉至

ปี

严

苾

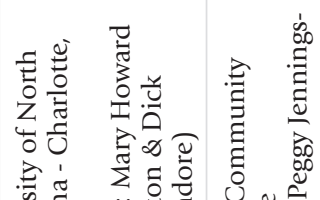

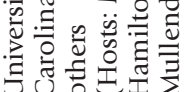

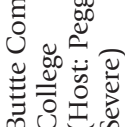

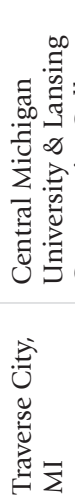

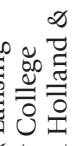

草

ㅊ.

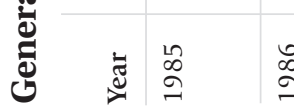

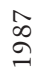

$\stackrel{\infty}{\infty}$

$\stackrel{2}{\stackrel{\infty}{2}}$

ڤે 


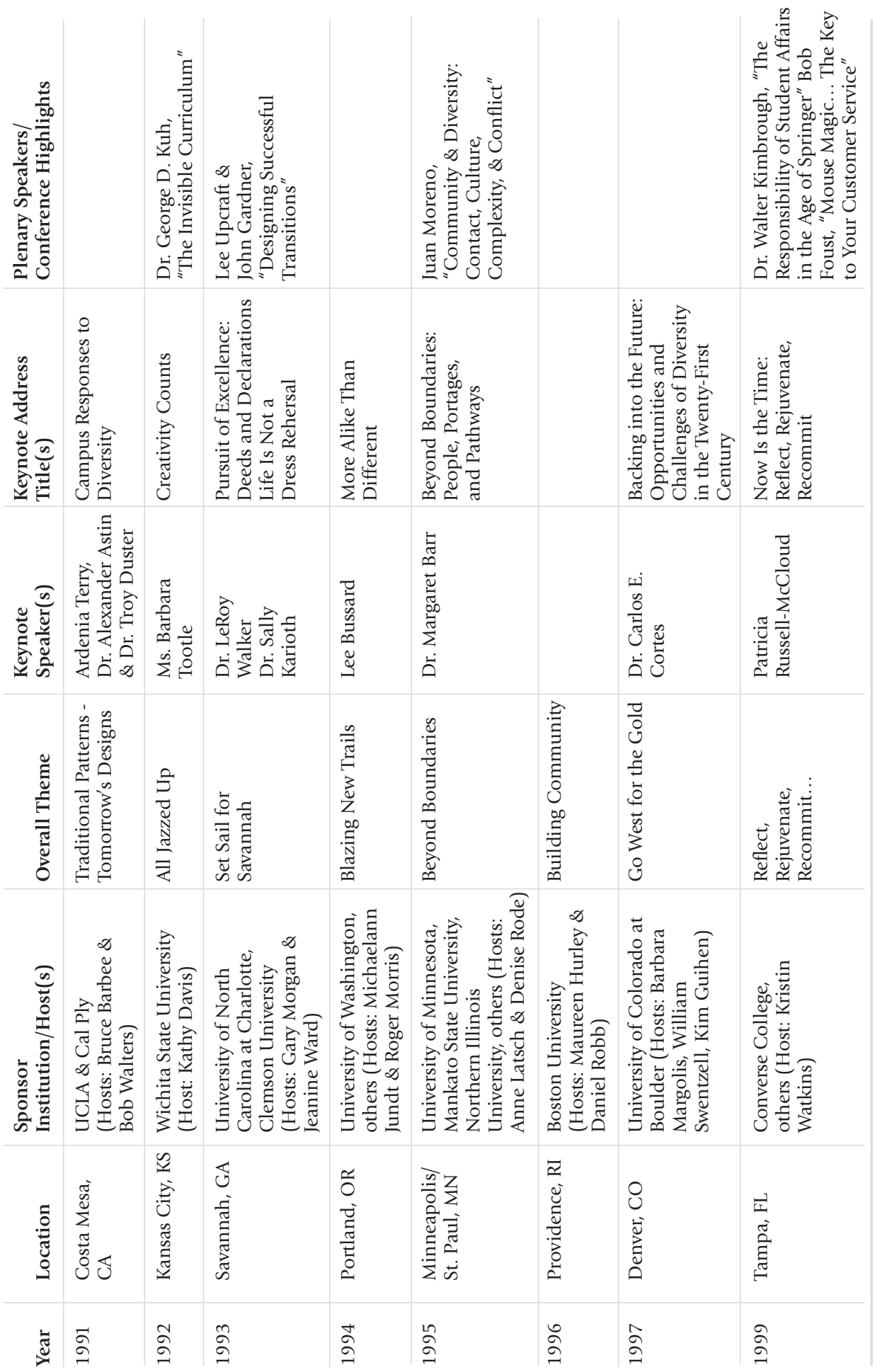




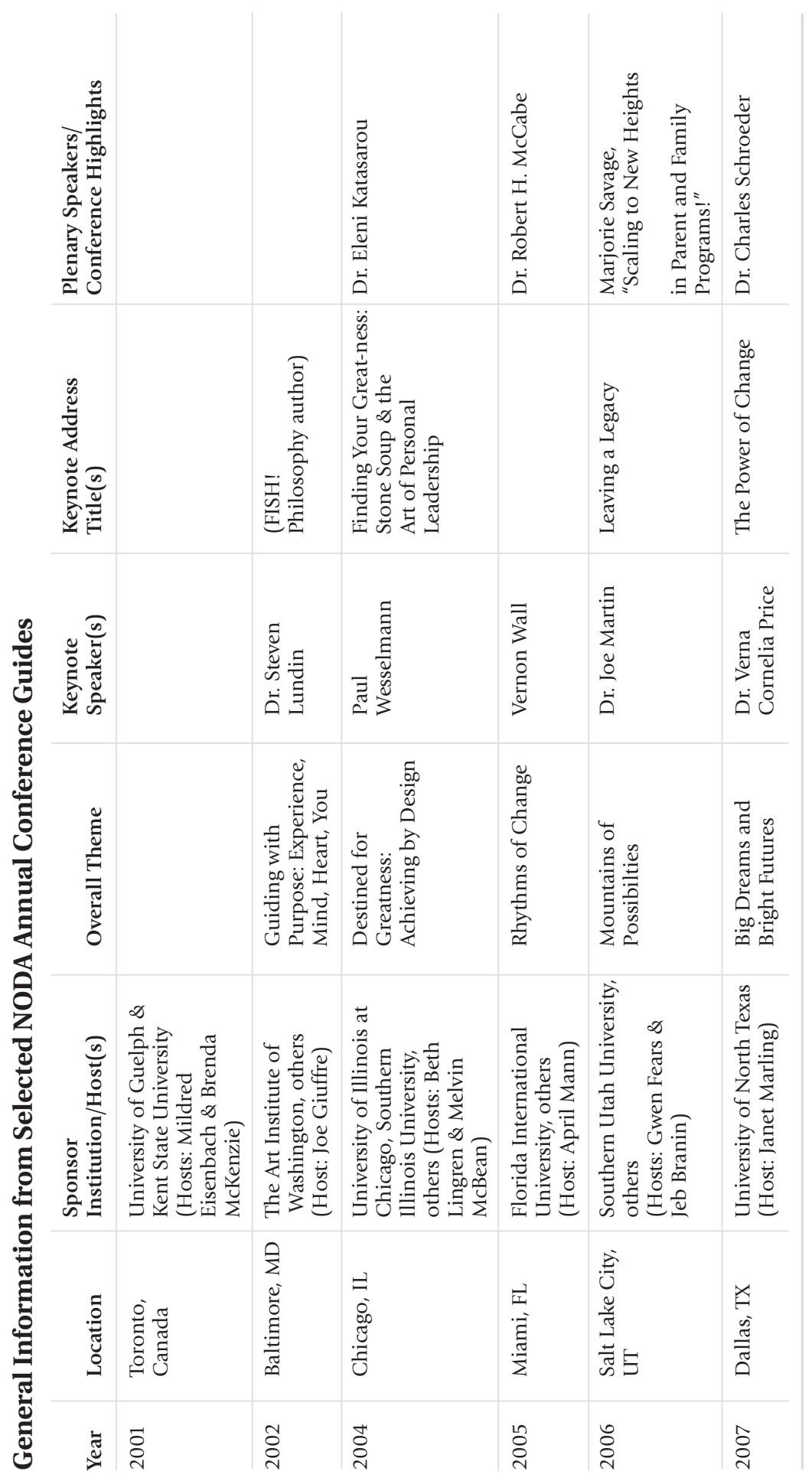




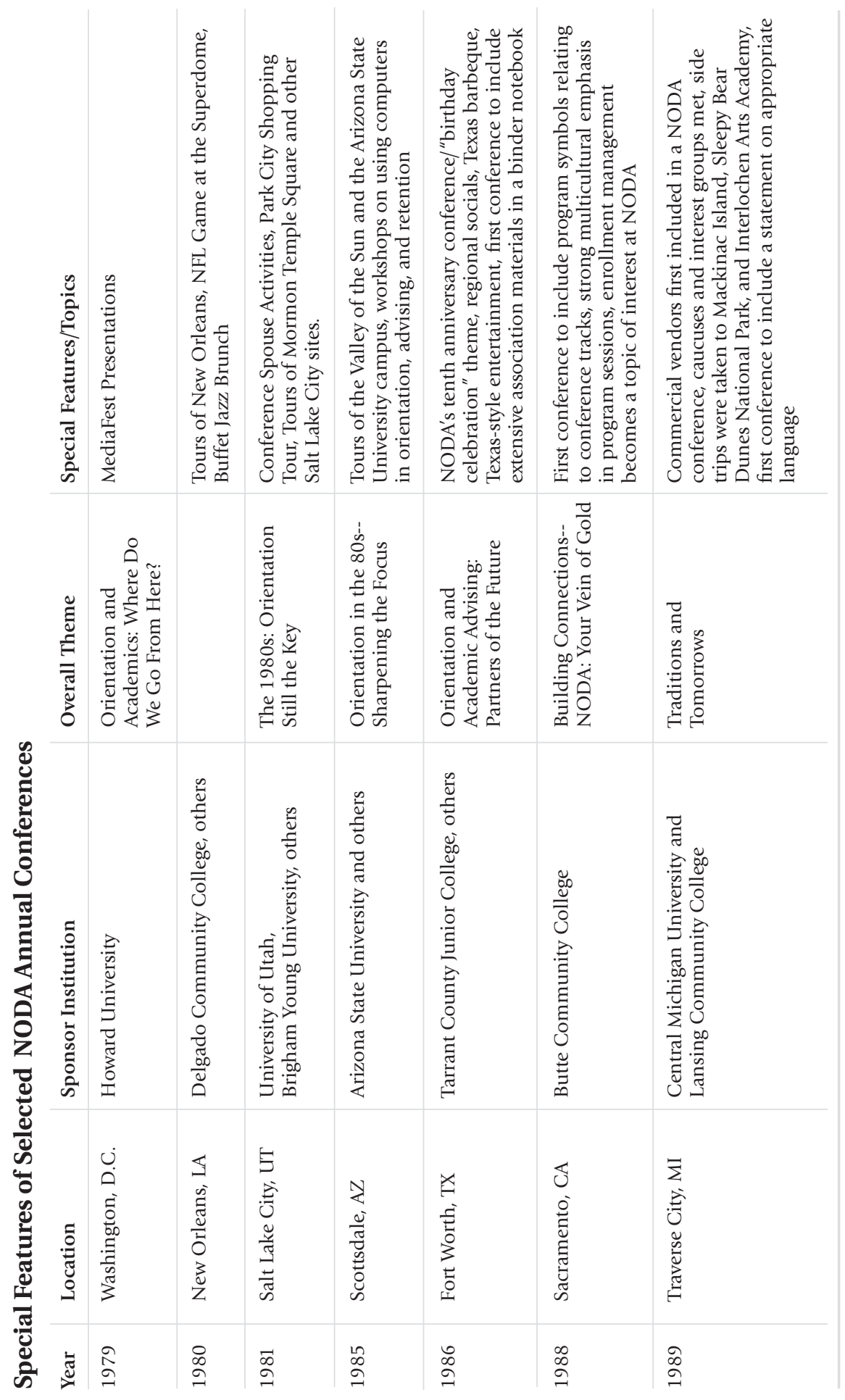




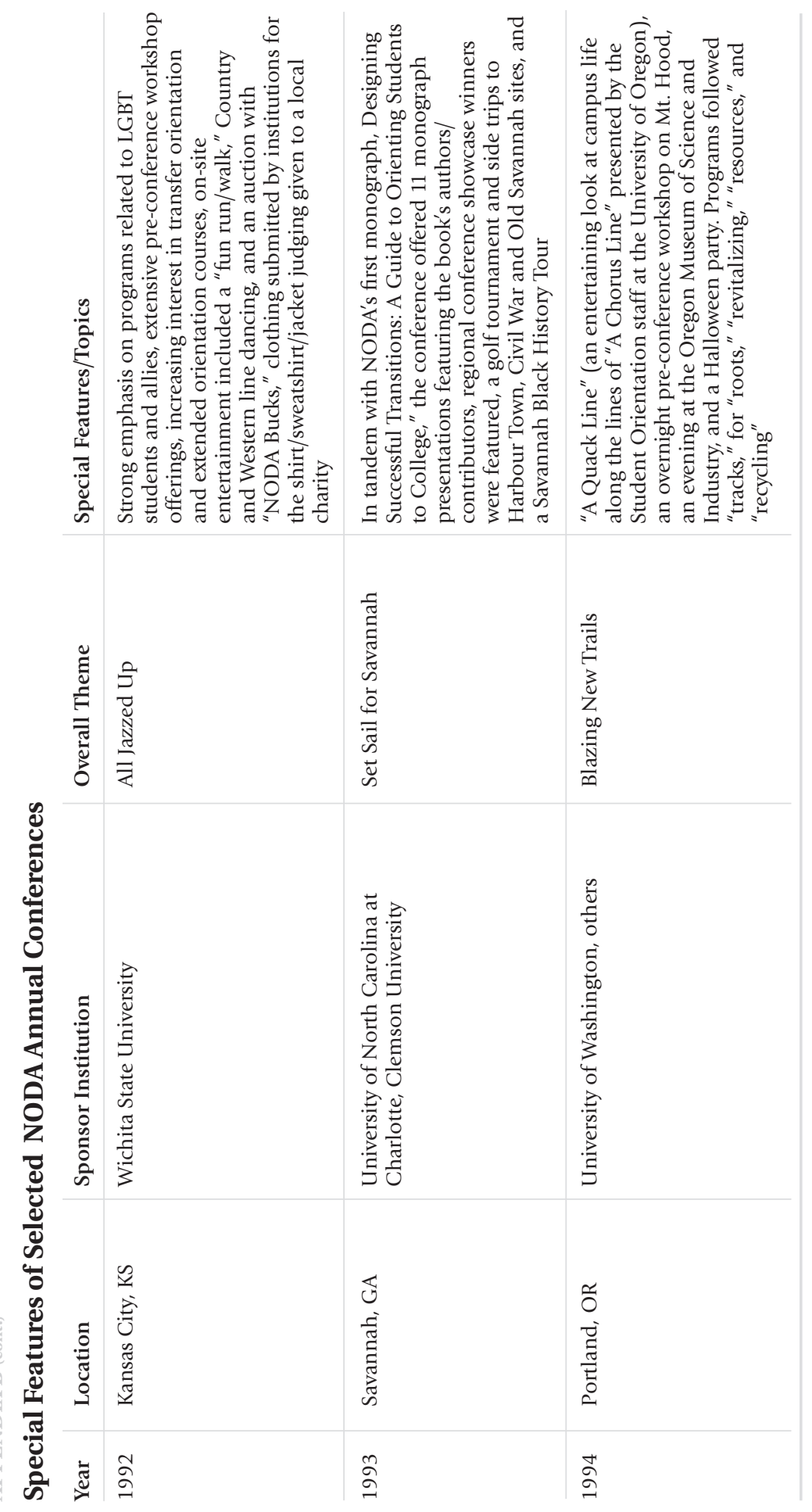




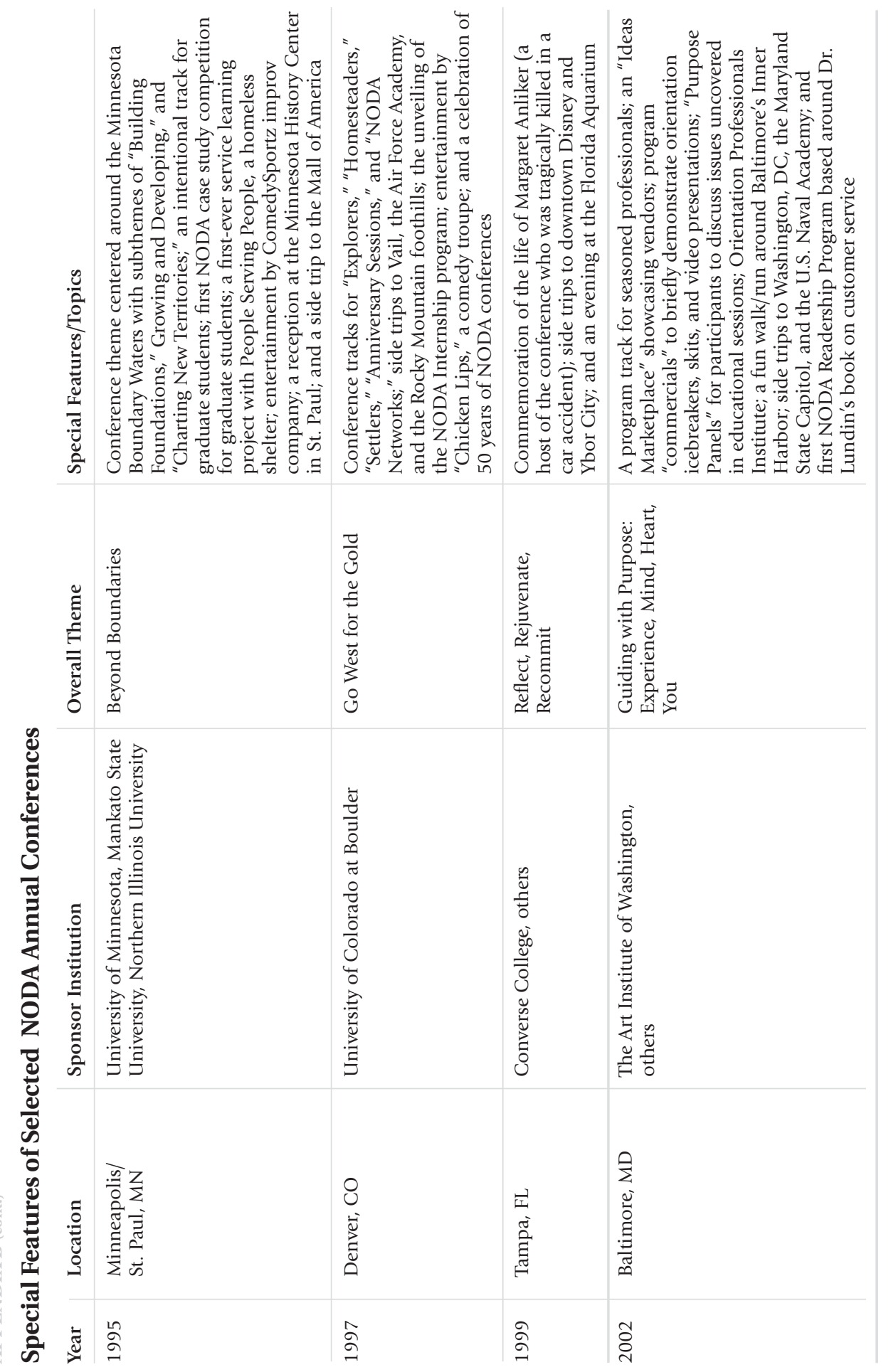




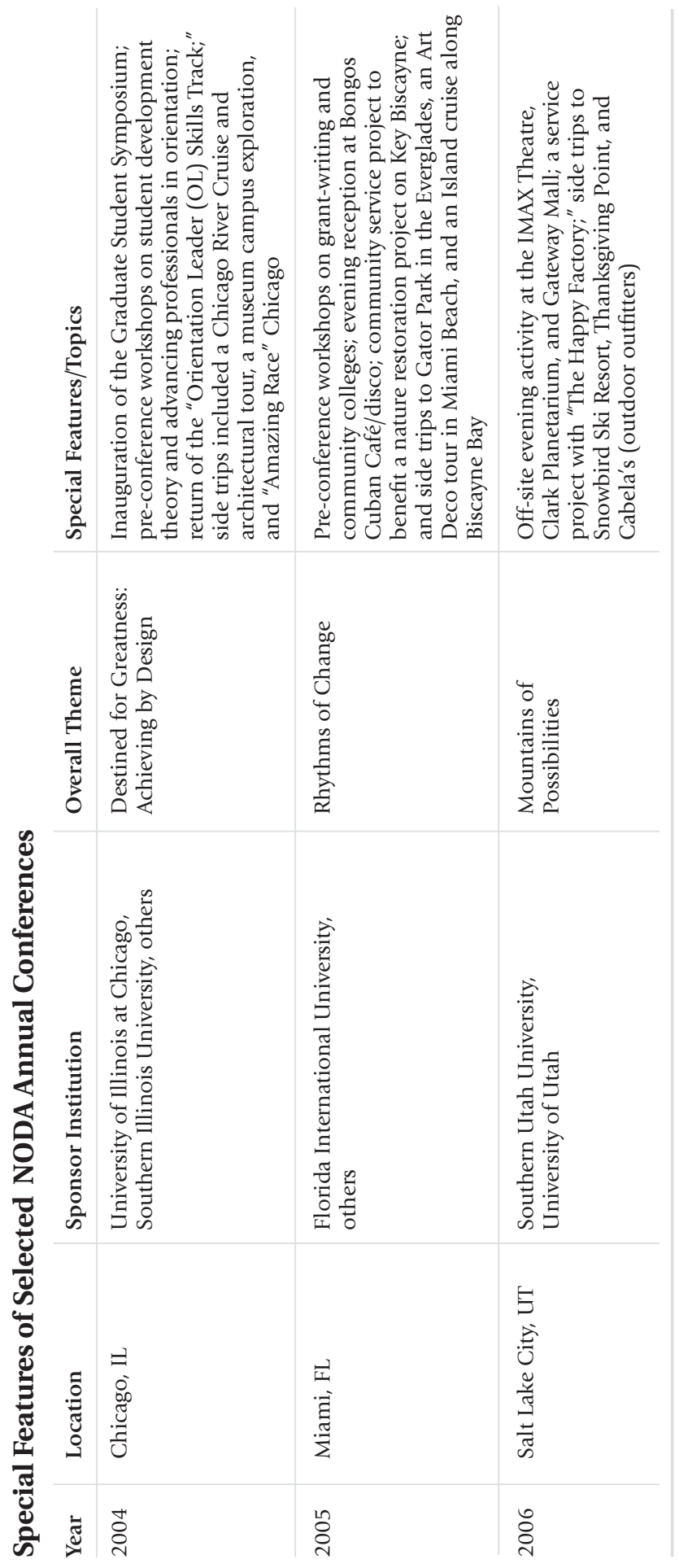

